\title{
Coeliac Disease in North Indian Children*
}

\author{
B. N. S. WALIA, M.D., D.C.H. ; J. K. SIDHU, M.B., .B.S.; B. N. TANDON, M.D. \\ O. P. GHAI, M.D., D.C.H. ; S. BHARGAVA, M.D., D.M.R.D.
}

Brit. med. F., 1966, 2, 1233-1234

Coeliac disease is believed to be very rare in tropical countries (Trowell and Jelliffe, 1958 ; Nelson, 1959). An authentic case of this disorder has so far not been documented in a child of Indian origin. This communication places on record 10 children with steatorrhoea, seven of whom fulfilled the confirmatory criteria for the diagnosis of coeliac disease, while in the remaining three the results of investigation and the course of the illness were highly suggestive.

\section{Present Investigation}

Materials and Methods.-The patients were 10 children aged 3-14 years; six were males and four females. Haemograms and microscopical and bacteriological examination of stools were carried out. Stools were analysed for fat content (van de Kamer et al., 1949). D-Xylose in the urine was estimated by the method of Roe and Rice (1948). Barium-meal examinations of the small bowel were made with a nonflocculating medium (Micropaque). Jejunal biopsy was performed in seven children with Rubin multipurpose tube (Rubin et al., 1960). The children were started on a gluten-free diet.

- From the Departments of Paediatrics, Medicine, and Radiology, All India Institute of Medical Sciences, New Delhi.
Folic acid or antibiotics were not given to any of them. The clinical and biochemical response was assessed after a period of 12 or more weeks. An attempt to induce enteropathy by reintroduction of gluten in the diet was made in six patients who had been in remission for periods varying from two to six weeks.

Observations.-Failure of growth and the passage of stools with the characteristics of steatorrhoea were observed in all patients. All were anaemic. Behavioural changes and evidence of avitaminosis were each noted in three patients. All the patients had steatorrhoea and diminished D-xylose excretion. A deficiency pattern of the small bowel was demonstrated radiologically in all the cases. Jejunal biopsy was abnormal in the seven subjects studied. Details of the observations are summarized in the Table.

\section{Comments}

All the children presented with growth failure and diarrhoea which had started in the second or third year of lifethe period at which mixed feeds are introduced into the diet of an Indian child. That the diarrhoea was not due to the common bacterial or parasitic infections and infestations is suggested by

Summary of Cases

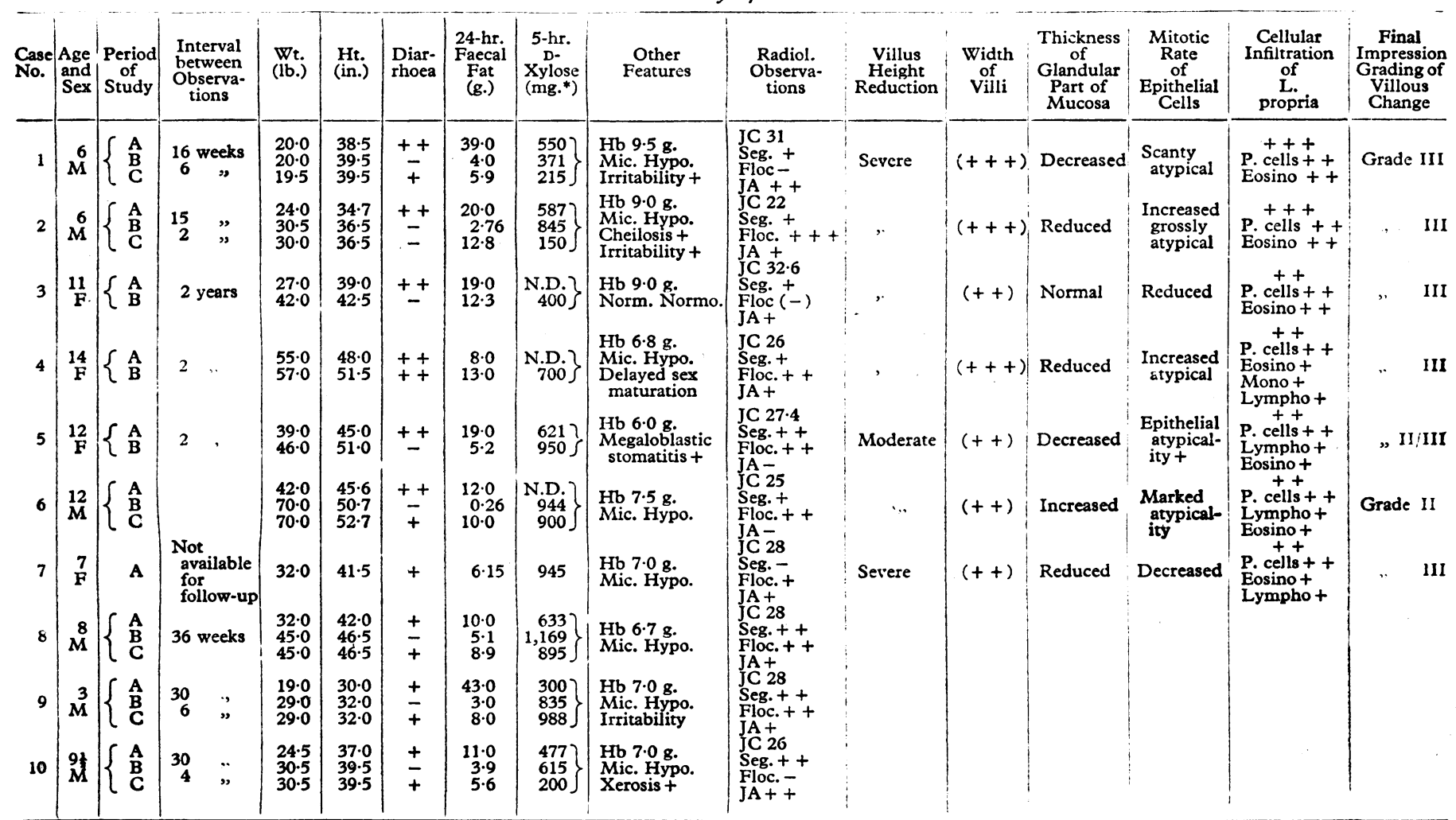
$A=$ On admission. $B=$ After gluten-free diet. $\mathrm{C}=\mathrm{On}$ gluten reintroduction. N.D. $=$ Not done. Seg. $=$ Segmentation. Floc. $=$ Flocculation. JA $=$ Jejunal atrophy.
Mic. Hypo. $=$ Microcytic hypochromic. jejunal calibre in 25 normal children, $22 \mathrm{~mm}$ ) 
the normal results of microscopical and culture examination of the stools. Barium-meal examination of the intestine helped to exclude rarer causes of malabsorption such as malrotation of the gut, regional ileitis, and ileocaecal tuberculosis.

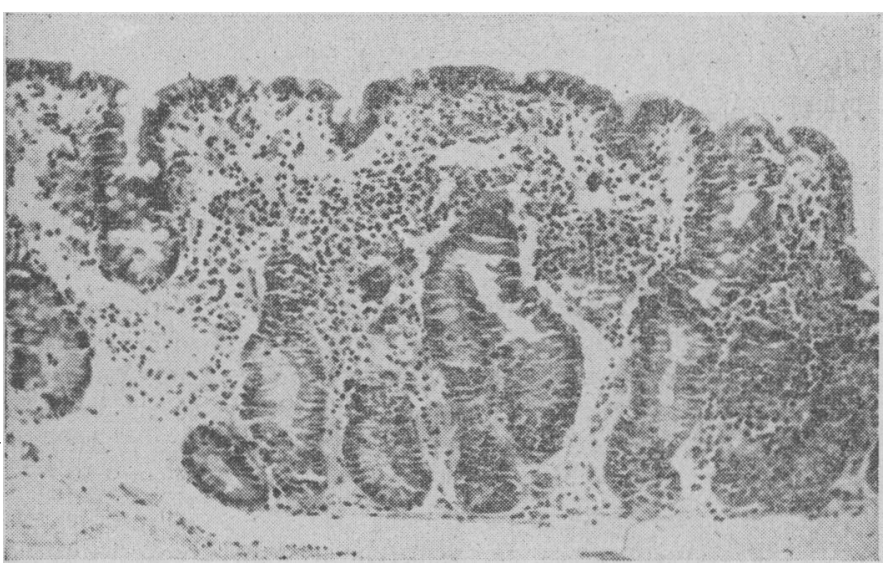

Fig. 1.- Jejunal mucosal biopsy from Case 2. Showing a marked reduction in villus crypt ratio and fusion of the villi. Increased infiltration of the lamina propria by chronic inflammatory cells, glandular hyperplasia, and atypicality of the epithelial cells are also evident (subtotal villous atrophy). Grade III change. (H. and E. $\times 96$.)

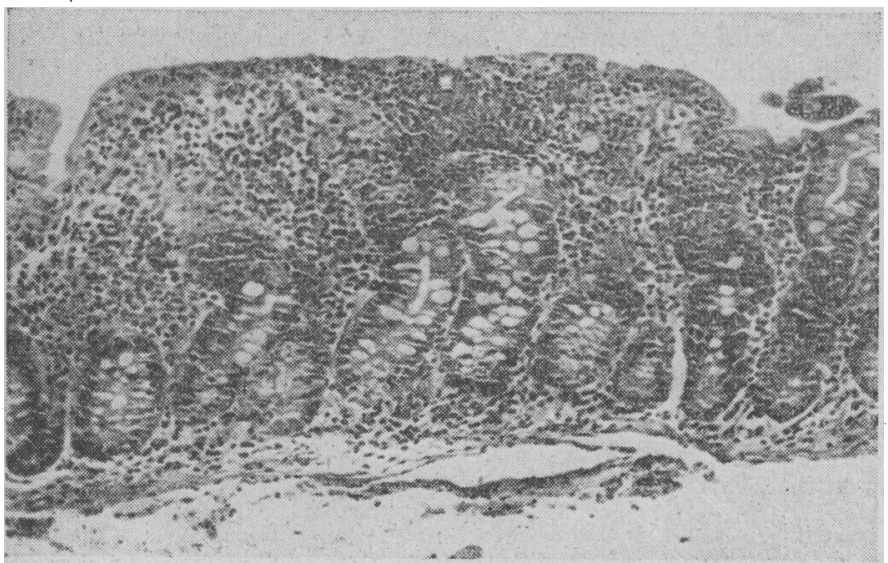

Fic. 2. - Jejunal mucosal biopsy from Case 7. Showing advanced atrophy of the villi with an almost flat mucosa. Inflammatory cell infiltration of lamina propria, glandular abnormalities, and epithelial cell atypicalities are prominent (total villous atrophy). Grade III change. (H. and E. $\times 96$.)

Although special tests to exclude mucoviscidosis were not performed, the late onset of diarrhoea, the absence of pulmonary symptoms, the impaired D-xylose absorption, and, finally, the response to gluten exclusion and reintroduction militate against this possibility. The mucosal pattern of the intestinal biopsy specimens resembled the one observed in idiopathic steatorrhoea and coeliac disease (Rubin, 1961 ; Cameron et al., 1962). Though some workers (Sprinz, 1962) doubt the specificity of the histological lesions, many others (Shiner and Doniach, 1960 ; Anderson, 1960 ; Ross and Nugent, 1963 ; Hubble, 1963) consider it to be quite pathognomonic of coeliac disease.

Eight of the nine patients who could be followed up showed a marked clinical improvement within a few weeks of exclusion of gluten from the diet. In all eight this was accompanied by a reduction in the daily fat loss. The final test of coeliac disease is stated to be the ability of gluten to induce a relapse (B.M.f., 1962). This was demonstrated in all six children in which it was attempted (Cases 1, 2, 6, 8, 9, and 10).
Heiner and Lahey (1962) recommended that the presence of at least two of the three following characteristics-namely, steatorrhoea, impaired carbohydrate absorption, and mucosal biopsy evidence-was enough justification for a trial with gluten-free diet. Cameron et al. (1962) defined the diagnostic criteria of coeliac disease as (1) clinical manifestations, (2) exclusion of other causes of steatorrhoea, (3) radiography showing dilated small intestine, (4) clinical and biochemical remission on a gluten-free diet, and (5) relapse on reintroduction of gluten. All the cases presented fulfil the first four of the above criteria. In addition, seven children showed the histological lesions suggestive of coeliac disease (Cases 1-7): The three

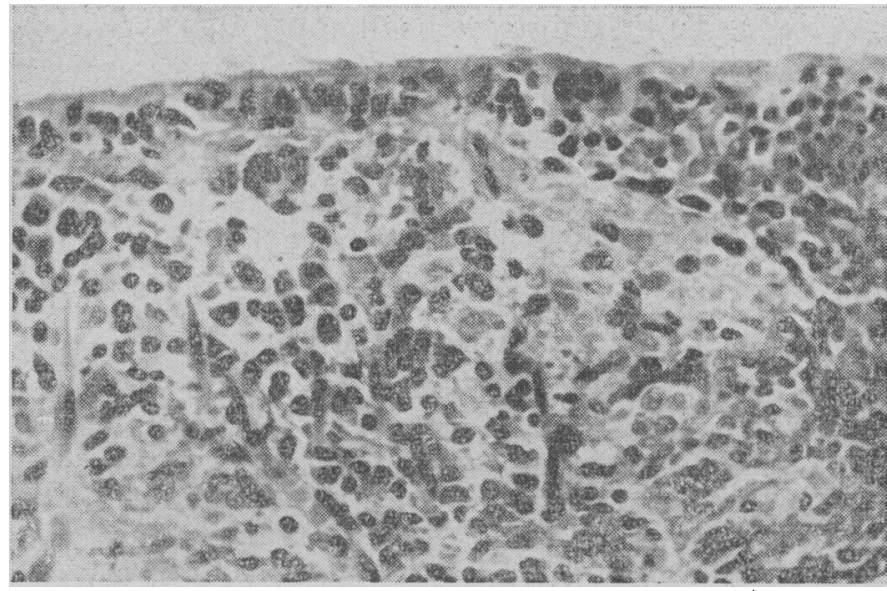

FIG. 3.-Further magnification of Fig. $2(\times 240)$ to demonstrate atypical epithelial cells, which have acquired an almost cuboidal shape.

children in whom a jejunal biopsy could not be performed showed a clinical and biochemical relapse on reintroduction of gluten in the diet (Cases 8-10).

\section{Summary}

Ten cases of coeliac disease in children of Indian origin are described. The clinical, biochemical, and histological data in favour of the diagnosis are discussed. The effect of gluten withdrawal and gluten reintroduction was used as an additional support for the diagnosis of coeliac disease in these children.

\section{REFERENCES}

Anderson, C. M. (1960), Arch. Dis. Childh., 35, 419.

Brit. med. f., 1962, 2, 1241 .

Cameron, A. H., Astley, R., Hallowell, M., Rawson, A. B., Miller, C. G. French, J. M., and Hubble D. V.' (1962). Quart. f. Med., 31, 125.

Heiner, D. C., and Lahey, M. E. (1962). Pediat. Clin. N. Amer., 9, 975 Hubble, D. (1963). Brit. med. F., 2, 701.

Nelson, W. E. (1959). Text Book of Pediatrics, 7th ed., p. 722. Saunders, Philadelphia.

Roe, J: H., and Rice, E. W. (1948). f. biol. Chem., 173, 507.

Ross, J. R., and Nugent, F. W. (1963). Med. Clin. N. Amer., 47, 417.

Rubin, C. E., Brandborg, L. L., Phelps, P. C., and Taylor, H. C. (1960). Gastroenterology, 38, 28.

- (1961). Ann. Rev. Med., 12, 39.

Shiner, M., and Doniach, I. (1960). Gastroenterology, 38, 419.

Sprinz H (1962) Fed Proc 21, 57.

Trowell, H. C., and Jelliffe, D. B. (1958). Diseases of Children in the Subtropics and Tropics, p. 344. Arnold, London.

van de Kamer, J. H., ten Bokkel Huinink, H., and Weyers, H. A. (1949). f. biol. Chem., 177, 347. 